\title{
PAUL SINGER: MEMÓRIAS DE UMA EXPERIÊNCIA APRENDENTE ${ }^{1}$
}

Valmor Schiochet ${ }^{2}$

Universidade de Brasília (UnB)

e-mail

\section{Resumo}

O texto relata as memórias e expereincias do autor com Paul Singer. Descreve sua trajetória em vários momentos históricos ao lado de Paul Singer como membro de sua equipe. Apresenta suas reflexões sobre o impacto de Singer com sua força ético-política e de direção moral e intelectual da sociedade.

Palavras-chave: Histórico; Economia Solidária; Politica Economica.

\section{PAUL SINGER: MEMORIES OF A LEARNING EXPERIENCE}

\begin{abstract}
The text recounts the author's memories and experiences with Paul Singer. Describes his trajectory in several historical moments alongside Paul Singer as a member of his team. It presents his reflections on the impact of Singer with his ethical-political force and of moral and intellectual direction of the society.
\end{abstract}

Keywords: Historic; Solidarity Economy; Economic Policy.

\footnotetext{
1 Tive o prazer de participar de uma mesa em homenagem ao professor Paul Singer no XII Encontro de Economia Catarinense, realizado em Lages/SC no último mês de maio. Na oportunidade falei sobre impressões sobre a presença do Professor na minha recente trajetória de vida. Agora tenho a oportunidade de apresentar minhas reflexões sob forma de texto a pedido do Professor Armando Lisboa a quem devo muito da minha aproximação com a autogestão e a economia solidária

${ }^{2}$ Doutor em Sociologia pela Universidade de Brasília (UnB), professor do Departamento de Ciências Sociais e Filosofia e do Programa de Pós-Graduação em Desenvolvimento Regional e da Incubadora Tecnológica de Cooperativas Populares na Universidade Regional e ex-diretor de Estudos e Divulgação da Secretaria Nacional de Economia Solidária.
}

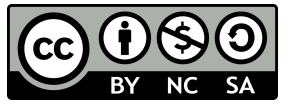

P2P \& INOVAÇÃO, Rio de Janeiro, v. 5 n. 1, Ed. Especial, p.53-60, 2018. 


\section{PAUL SINGER}

Paul Singer é um dos maiores economistas que tivemos, mas em verdade foi um grande educador a semelhança de Paulo Freire. Para ele tudo se traduzia em oportunidade de aprendizagem. Chegou a definir a economia solidária como um ato pedagógico em si. Assim podemos dizer também que a convivência com o professor é uma experiência aprendente.

Minha relação com Paul Singer ocorreu em três momentos distintos. Dois momentos de encontro e o terceiro quando por duas vezes tive oportunidade de compor a sua equipe na direção da Secretaria Nacional de Economia Solidária.

Em 1997, na condição de Secretário Municipal de Trabalho, Renda e Desenvolvimento Econômico do município de Blumenau recorri ao Professor Singer para encontrarmos alguma alternativa política para enfrentar a grave crise de desemprego que se abatia sobre a cidade. A motivação para este encontro foi o fato de que em sua tese de doutoramento sobre industrialização e urbanização o professor realizou uma reflexão específica sobre o processo de industrialização de Blumenau. A ideia era que ele revisitasse sua tese quase 30 anos depois.

Em verdade está motivação foi frustrada pois Singer já estava em outro momento de sua vida intelectual e política. Mas frustação se transformou em motivação. Encontramos outra razão para sua estada em Blumenau naquele ano de 1997: as suas reflexões relativas a autogestão e a economia solidária como proposta para o combate do desemprego.

No ano anterior, desafiado a apresentar um programa para as políticas municipais de enfrentamento do desemprego e pobreza, me deparei com reflexões bastante novas para mim tomadas de alguns escritos de José Luis Coraggio, Luiz Razetto e Paul Singer sobre a existência de uma economia fundamentada na solidariedade, na cooperação e na autogestão.

Tema que de forma bastante tangencial incluí na minha tese de doutoramento sobre os dilemas conceituais relativos à sociedade civil no Brasil.

Este contexto possibilitou a aproximação com o professor Singer para aprofundar a reflexão de como na prática poderíamos utilizar da autogestão, das cooperativas de trabalho e das mais diversas formas coletivas de auto-organização dos trabalhadores e comunidades pobres para enfrentamento da crise. $\mathrm{O}$ que naquele momento passou a ser denominado por Singer de Economia Solidária, conceito que segundo ele foi utilizado por Aloísio Mercadante em 1996 e que Paul Singer assumiu e passou a defender teórica e politicamente.

Um conceito para denominar uma pluralidade de práticas organizativas promovidas pela Cáritas Brasileira em seus projetos alternativos comunitários (PACs), pelo Movimento dos Sem Terra nas Cooperativas dos Assentados da Reforma Agrária, pelo movimento dos 
agricultores familiares com suas cooperativas de crédito, industrialização e comercialização e pela Associação Nacional de Trabalhadores de Empresas de Autogestão e Participação Acionária (ANTEAG).

A presença do Singer em Blumenau em 1997 nos possibilitou a aproximação com este amplo movimento experimental de auto-organização dos trabalhadores e a implementação de um programa municipal de apoio as formas cooperativas e autogestionárias de organização econômica. No meu entendimento uma experiência pioneira de política municipal voltada à organização da população desempregada e pobre. É importante reconhecer que aqui em Lages/SC, por ocasião do governo de Dirceu Carneiro nos anos 80 ocorreram iniciativas muito valiosas nesta direção.

Singer foi decisivo para que eu mergulhasse no campo da economia solidária e assim encontrasse uma conexão de sentido com anterior interlocução que mantive com Cláudio Nascimento e Armando Lisboa em meados dos anos 80 quando empreendemos a mobilização de coletivos pela autonomia e autogestão nas regiões de Joinville, Florianópolis, Lages e Criciúma.

Após meu afastamento da Prefeitura Municipal e consequente retorno à Universidade Regional de Blumenau tive a oportunidade de conhecer o movimento que estava acontecendo nas Universidades Brasileiras com o surgimento da Unitrabalho, uma Rede Interuniversitária de Pesquisas e Estudos sobre o Mundo do Trabalho sob a ótica dos trabalhadores. Lá estava também nosso professor Singer e seu esforço de colaboração e de busca de agregação de todos os esforços para a ampliação da capacidade militante da academia em favor dos trabalhadores, em especial aquelas e aqueles em condição de maior precariedade. Vi em Singer uma enorme crença sobre o papel transformador da universidade, dos intelectuais, da academia. Sob a coordenação acadêmica de Paul Singer representei a Unitrabalho num grupo de trabalho que coordenou a primeira pesquisa nacional sobre a economia solidária. Deste Grupo também participou o professor Luiz Inácio Gaiger o qual posteriormente organizou a publicação dos resultados da pesquisa sob o título "Sentidos e Experiências da Economia Solidária no Brasil”. Singer sempre manifestou que após ter publicado artigo na Folha de São Paulo, onde pela primeira vez utilizou a expressão "economia solidária" para descrever as iniciativas coletivas de trabalhadores contra o desemprego e a miséria passou a receber inúmeros relatos de que o conceito que ele tinha inventado já estava sendo vivido na prática por muito tempo no Brasil. Durante o grupo de trabalho o professor estava entusiasmado com a ideia de que havia uma realidade pulsante de caráter socialista disseminada em todo o 
território. O que demonstraria a pertinência de suas ideias. A cada relato, a cada descoberta manifestava enorme satisfação e curiosidade em conhecer mais.

Também é desta época que percebi o quanto o professor Singer era um defensor da unidade. Frente as dificuldades de entendimento envolvendo as diversas organizações e instituições acadêmicas e sindicais sua disposição sempre foi a de estar em todos os espaços, valorizar todas as iniciativas, relativizar as disputas em torno de pretensas verdades ou razões que justificavam as divisões. Era preciso avançar e avançar juntos era um princípio importante para ele. Além de da crença no coletivo manifestava uma enorme crença na capacidade humana do entendimento pelo convencimento em torno de argumentos válidos.

Deste momento também fui percebendo que o Professor representava uma tradição de pensamento e de movimento político. Para ele a economia solidária era expressão do movimento operário em oposição ao capitalismo. Toda referência histórica inicial das falas de Singer sobre a economia solidária estava na Sociedade Equitativa dos Pioneiros de Rochdale, fundada em 1844. E o pioneiro citado quase sempre era Robert Owen (1771-1858).

Praticamente nunca fazia referência ao socialismo francês ou outros movimentos socialistas. No pensamento marxista tinha como referência Rosa Luxemburgo e sua defesa de pensar e praticar o socialismo a partir da democracia. Para ele, não há socialismo sem democracia. O socialismo é a radicalização da democracia. A base do socialismo é a autogestão. Bem, assim não conheci o Paul Singer economista, apenas conheci o Paul Singer da economia solidária e do socialismo autogestionário. Um defensor intransigente da democracia.

O terceiro momento começou com um telefonema recebido em meados do mês de fevereiro ou de março de 2003. Após ser anunciada a criação da Secretaria Nacional de Economia Solidária e da decisão do presidente Lula de que ela seria coordenada pelo Professor Singer recebi um inesperado telefonema, e do outro lado da linha o professor fazendo o convite para que eu compor a equipe da Secretaria Nacional de Economia Solidária. Ainda não tinha claro qual o papel deveria cumprir pois a Secretaria ainda estava sendo pensada. Mas manifestou que gostaria da minha colaboração para a construção de uma política de formação e educação em economia solidária.

Bem, a experiência com a SENAES foi longa. Um primeiro momento de 2003 até início de 2007 e um segundo momento de 2011 até 2016. Agora sim experiência de convivência mais cotidiana e não esporádica com o Secretário Singer, mas sempre professor.

Primeiramente o que me chamou a atenção foi a determinação com a qual assumia as decisões e posições. Frente a uma dificuldade política que adiou minha nomeação por mais de 
três meses e minha quase desistência de honroso convite ele manteve-se firme e forte na defesa de que a equipe fora por ele escolhida e deveria ser mantida sem exceção. Não tinha dúvida na defesa de sua equipe e das pessoas que havia escolhido. Além do esforço permanente para manter a unidade de todas e todos.

Neste momento vou me limitar a abordar duas dimensões de profunda aprendizagem desta experiência de convivência com o professor Paul Singer na condição de Secretário Nacional. A primeira diz respeito a concepção e prática de política pública. A segunda impressões gerais sobre o ser humano Paul Singer.

Para Singer a economia solidária era uma economia da sociedade civil, uma economia das trabalhadoras e dos trabalhadores, uma economia das comunidades. Esta era a economia solidária autêntica pois resultado da livre adesão das sócias e dos sócios. Esta economia deveria ser apoiada pelo Estado. Em muitas vezes utilizava a expressão “ajudada" pelo Estado. Toda economia solidária cuja origem era motivada pela ação direta do Estado era vista pelo Professor como uma "maneira artificial” de criar economia solidária.

O papel do Estado era fundamentalmente o de apoiar, o de alocar recursos financeiros e institucionais para fortalecer a autogestão, transferir recursos para as organizações da sociedade civil que já fazem e sabem fazer economia solidária. Ao Estado caberia a tarefa de dar visibilidade, disseminar as experiências realizar um intenso processo formativo a começar pela própria equipe responsável pela política de economia solidária, pelo Ministério no qual a Secretaria estava alocada e de todo o Governo Federal. Não por acaso uma das iniciativas mais entusiasmadas foi nossa parceria com a Escola Nacional de Administração Pública (ENAP) com a oferta de um curso de formação em economia solidária para gestores dos diversos ministérios e órgãos do governo federal. Os momentos de maior satisfação eram aqueles de diálogos com sua equipe, os momentos de formação. Geralmente ao termino das atividades ele dizia com satisfação: - "aprendi muito com vocês hoje". Para Singer o fomento à economia solidária era basicamente acesso ao conhecimento, à educação, a troca de experiências.

Outro elemento característico da política nacional de economia solidária pode ser resumido em uma expressão recorrente em suas falas: - o sentido da política de economia solidária é promover o "resgate humano". Singer pensava na economia solidária como expressão de um setor organizado da sociedade civil, em especial de todo o movimento articulado em torno do Fórum Brasileiro de Economia Solidária. Caberia aos participantes da economia solidária não defender uma política para si (suas bases) mas defender que a economia solidária fosse a política para toda a população, em especial para a inclusão e 
emancipação da população mais vulnerabilizada, desumanizada e estigmatizada. Por ocasião do Fórum Nacional do Trabalho (FNT) fez uma defesa contundente de que o trabalhador não poderia ser confundido com o assalariado, o desempregado. Mas trabalhador são todas e todos que buscam dignidade pelo reconhecimento de sua atividade laboral. A presença das prostitutas e suas organizações nas atividades do FNT manifestava este sentido amplo dos desafios para o mundo do trabalho. O resgate humano esteve presente na aproximação da Secretaria Nacional de Economia Solidária com os beneficiários do Fome Zero, depois Bolsa Família, dos usuários da saúde mental, dos catadores de material reciclado, dos moradores de rua, dos povos e comunidades tradicionais, dos encarcerados, dos jovens e das mulheres. Mulheres. Singer sempre um feminista convicto. Impressionava pela defesa das mulheres e de seus direitos e pela denúncia do machismo. Singer via na economia solidária uma economia feminista para além de ser feminina pois a maioria de participantes da economia solidária e muitas de suas lideranças são mulheres.

Alguns argumentos do Singer quanto a política nacional de economia solidária nos desafiava constantemente. Um dizia respeito ao crédito que era uma reivindicação ampla do movimento de economia solidária quanto a necessidade da abertura de linhas de crédito fortemente subsidiadas e simplificadas para os pobres organizados na economia solidária. Singer manifestava pouca vontade de "brigar" para o acesso aos fundos públicos. Entendia que a economia solidária já havia descoberto os instrumentos adequados de crédito e financiamento. Eram as finanças solidárias organizadas nas cooperativas de crédito, nos fundos rotativos solidários e nos bancos comunitários de desenvolvimento. Ao invés de levar crédito para a economia solidária, defendia que deveríamos levar as finanças solidárias ao crédito. O que não impediu de buscar uma importante parceria com o BNDES para um programa de fortalecimento da autogestão e da economia solidária no país.

Outra dúvida e contra-hipótese constante dizia respeito as compras governamentais. Também uma reivindicação do movimento consubstanciada nas deliberações das conferências nacionais de economia solidária. A tese era de que as compras governamentais e aquisições institucionais constituiriam uma ação política decisiva para possibilitar abertura de mercado aos empreendimentos da economia solidária. Singer, por sua vez, argumentava que o mercado institucional era uma espécie de mercado protegido e sua preocupação de que todo mercado protegido teria como consequência a redução da criatividade da economia solidária. Entendia que o mercado tinha esta importante função de estimular a criatividade e o adequado atendimento das expectativas dos consumidores. Somente com muita argumentação e com os exemplos do Programa de Aquisição de Alimentos (PAA) e do Programa Nacional de 
Alimentação Escolar (PNAE) é que ele foi convencido da importância das compras governamentais para omentar a economia solidária.

Enfim, acho que havia nele uma coerência entre sua visão da autenticidade da economia solidária da sociedade civil e o risco do artificialismo produzido pela excessiva presença do Estado.

Para terminar este breve relato faço algumas referências a alguns aspectos que me impressionaram muito no Professor e Secretário Paul Singer.

Sua força ético-política, acho que no sentido gramsciano de direção moral e intelectual da sociedade. Singer expressava uma força impressionante. Em sua humildade e sabedoria era reverenciado. Incólume perante crises de governo e ministeriais. Um secretário nacional que manteve à frente da Secretaria de 2003 até 2016. Quatro governos, dois presidentes, oito ministros, entre titulares e interinos, dois diferentes partidos na condução do Ministério. Deixou a Secretaria já com saúde bastante debilitada, mas a deixou com tristeza pois sem dúvida dela vinha boa parte da força que o animava a enfrentar dificuldades.

Um ser humano coerente. Foi impressionante a disposição de em plena crise do Governo Dilma conceder uma entrevista para a Folha de São Paulo (FSP, 10/06/2015) com críticas contundentes à política econômica do governo. A mensagem foi de que "Dilma estava fazendo a política que Aécio prometeu fazer e que havia um risco enorme desta política levar à perda da base popular e social do governo". Não atribuía somente a culpa ao governo pois já denunciava a existência de uma greve dos capitalistas impondo forte austeridade à sociedade. Mais tarde, em outubro repetiu a análise em entrevista concedida para o Jornal Zero Hora (Zero Hora, 31/10/2015).

Um ser humano estudioso. Gostava de receber livros e artigos. Quando o tema despertava o seu interesse a leitura era imediata. Ao receber o material ao final do dia impressionava o fato de na manhã do dia seguinte ele nos chamar para comentar a leitura. Também gostava de escrever. Após alguma reflexão coletiva sobre temas relativos a conjuntura ou a política de economia solidária no dia seguinte aparecia o Singer com um texto redigido. Era impressionante ver uma pessoa com sua idade dele e com fragilidades de saúde passar a noite em claro lendo ou escrevendo com tamanha intensidade.

Enfim, conheci Paul Singer como um ser feliz com a possibilidade de viver a experiência da economia solidária. Após uma reunião de trabalho no Palácio do Planalto caminhávamos até o carro a passos lentos. Tomei a liberdade de perguntar. - "Professor neste cenário difícil que estamos vivendo o que lhe anima a permanecer no governo, a trabalhar $e$ a acreditar no que estamos fazendo?" Resposta: - "Nunca imaginei em minha vida poder ver 
com os olhos e viver tudo o que acreditei em termos de experiência socialista. A economia solidária que vemos e apoiamos no Brasil e está presente no mundo todo é a experimentação efetiva do socialismo democrático que sempre defendi". Brilhavam os olhos de um ser aprendente e ensinante.

\section{REFERÊNCIAS}

SINGER, P. I. Introdução à economia solidária. São Paulo: Fundação Perseu Abramo, 2002.

SINGER, P. PT pode perder sua base social, alerta Paul Singer. Folha de São Paulo, São Paulo, 10 jun. 2015. Disponível em: https://www1.folha.uol.com.br/poder/2015/06/1640011pt-pode-perder-sua-base-social-alerta-paul-singer.shtml. Acesso em: 02 jul. 2015.

SINGER, P. Paul Singer: "Dilma está fazendo o que disse que Aécio faria". Zero Hora, Porto Alegre, 312015.2 Disponível em: https://gauchazh.clicrbs.com.br/geral/noticia/2015/10/paul-singer-dilma-esta-fazendo-o-quedisse-que-aecio-faria-4891433.html. Acesso em: 12 dez. 2015. 